Sonia Troitiño

Universidade Estadual Paulista (Unesp/

Marília)

\section{Avaliar para incorporar: políticas institucionais de
formação de acervo institucionais de
formação de acervo}

Appraise to incorporate: institutional policies for the constitution of collections

\section{Resumo}

Este ensaio se propõe analisar o impacto ocasionado pelo processo de incorporações de arquivos paralelo ao de gestão documental, em instituições de guarda de arquivos permanentes. Hoje em dia, diante dos novos paradigmas de gestão e custódia documental, arquivos e centros de documentação seguem adotando similarmente políticas de ampliação de seus acervos. Desse modo, pretendemos aqui refletir sobre a relação existente entre avaliação de documentos, porvia extraordinária à gestão documental, e formação de acervos institucionais, visando à preservação permanente de documentos.

Palavras-chave: Avaliação documental; Custódia; Arquivos históricos.

\section{Abstract}

This essay intends to analyze the impact caused by archive incorporation process parallel to documental management in institutions responsible for the custody of permanent archives. Nowadays, facing the new paradigms of documental management and custody, archives and documentation centers continues to adopt policies to expand their collections. Thus, we intend here to reflect about the relation between the appraisal of documents, which occurs beyond the documental management field, and the formation of institutional collections, aiming the permanent preservation of documents.

Keywords: Documental appraisal; Custody; Historical archives.
10 estudo apresentado neste ensaio faz parte do projeto de pesquisa Relação entre custódia e tratamento documental: investigação sobre procedimentos arquivísticos de incorporação de acervos, desenvolvido com auxílio do Conselho Nacional de Desenvolvimento Científico e Tecnológico Pesquisa - CNPq (Processo 443533/2014-8). Uma versão preliminar deste trabalho foi apresentada no XVII Encontro Nacional de Pesquisa em Ciência da Informação (XVII ENANCIB) com o título O Receber e o Organizar: interfaces entre avaliação documental e organização arquivística. 


\section{I n t r o d u s à 0}

ara além da gestão documental, caminho natural para a formação de acervos arquivísticos, os arquivos tradicionalmente sempre se valeram de processos paralelos de aquisição de conjuntos documentais definidos como de interesse social. Em decorrência, distintos procedimentos jurídicos de entrada de documentos, tais como recolhimento, depósito, doação, compra, entre outras possibilidades, podem ser adotados para o incremento de acervos em unidades de informação das mais diversas origens.

A discussão aqui desenvolvida leva em conta a reflexão feita a partir da relação entre custódia e tratamento documental, especialmente sobre a adoção de protocolos de trabalho em arquivos, de modo a racionalizar procedimentos de incorporação e disponibilização de documentação à sociedade. Embasados na teoria arquivística, em particular no que tange a identificação e avaliação documental, na discussão aqui proposta daremos ênfase aos documentos recebidos paralelamente ao sistema de gestão documental - por Ramón Alberch Fugueras (2003, p. 105-106) chamado de via extraordinária de incorporação, por fazer referência ao recolhimento de documentos não provenientes da Administração.

Segundo Alberch Fugueras, desde os anos 1980 existe uma política de captação de fundos externos às instituições produtọras de documentos, voltada para o recolhimento de arquivos de diversas origens: patrimoniais e pessoais, econômicos e de empresas, de entidades e associações e de órgãos extintos, com a vontade de enriquecer os arquivos públicos e diversificar a tipologia de seus próprios fundos. O autor alerta ainda que esses documentos se caracterizam por normalmente chegarem desordenados e em frágil estado de conservação. 
Justamente por isso, é imprescindível a existência de uma política de avaliação que identifique seu potencial interesse para a pesquisa (ALBERCH FUCUERAS, 2003).

A partir disso, pretendemos aqui apresentar algumas questões sobre o impacto ocasionado nos procedimentos de organização e disponibilização de documentos em instituições receptoras de documentos por sistema paralelo ao de gestão documental, como no caso das aqui abordadas: Arquivo Público do Estado de São Paulo (Apesp), Instituto de Estudo Brasileiros da Universidade de São Paulo (IEB/USP) e Centro de Documentação e Memória da Universidade Estadual Paulista (Cedem/Unesp). Dessa forma, identificar e analisar os procedimentos de incorporação de documentos a arquivos permanentes contribui para o entendimento da formação dos repositórios arquivísticos institucionais e sobre para a eleição de critérios de sua organização.

A questão da custódia apresenta-se como ponto fulcral da reflexão, pois a partir dela são estabelecidos os protocolos de trabalho a serem adotados no momento de acolhimento de um apresenta-se como ponto

fulcral da reflexão, pois a partir dela são estabelecidos

os protocolos de trabalho

a serem adotados no momento de acolhimento de um novo conjunto documental, levandose em considerando sua organização prévia e as tendências assumidas por instituições arquivísticas na atualidade. novo conjunto documental, levando-se em considerando sua organização prévia e as -tendências assumidas por instituições arquivísticas na atualidade.

O sistema de avaliação de documentos configura outro ponto a ser explorado. Quando fruto da administração, os parâmetros adotados pela gestão documental costumam ser claros e bem estudados. No entanto, os referenciais adotados para avaliar e valorar documentos provenientes de origens diversas (arquivos pessoais, familiares, coleções etc.) normalmente não possuem regras ou procedimentos metodológicos tão rígidos quanto os de arquivos institucionais. 


\section{Implicações da custódia e} formação de acervo

Do aleatório ao regrado, o momento de incorporação de novos conjuntos documentais pode ocasionar impacto no sistema de organização e acesso já estabelecido em um arquivo permanente. Oque em um primeiro momento pode parecer uma transferência tranquila de documentos, representa obrigatoriamente replanejamento logístico, muitas vezes classificatório, e dinamismo de determinados instrumentos de pesquisa.

Nesse panorama, a questão da custódia ganha destaque. Entre a propriedade e a guarda temporária, existem diversas possibilidades de responsabilidade legal sobre um acervo. Definir o status jurídico ao qual se encontra sujeito acaba por determinar, em larga medida, os procedimentos de tratamento arquivístico sobre o conjunto documental agregado, por parte da instituição custodiadora. Em geral, acervos cuja guarda é temporária são submetidos a protocolos de trabalho distintos dos incorporados, sob guarda definitiva.
O debate, aqui posto, iniciou-se com a discussão tratada no projeto de pesquisa Estudo Comparativo de Funções e Atividades em Instituições Análogas: a produção de inventários post-mortem nos Juízo Ordinário e Juízo de Órfãos. Desenvolvido entre 2017-2013, neste trabalho procuramos entender o contexto de produção documental, a tramitação impingida pela burocracia e as etapas do ciclo vital, acompanhando as mudanças da estrutura administrativa em conjunção com a produção documental de um mesmo tipo documental de diferentes proveniências. Buscávamos, assim, entender se a origem do documento interferia no modelo documental representado pelo tipo. O que pode ser percebido ao longo dessa pesquisa é que a incorporação de acervos de modo não planejado gera ônus ao sistema de organizaçẵo documental dos arquivos. Algumas vezes, como nos casos dos fundos acima citados, os princípios de proveniência e integridade arquivística são rompidos, lévando à descontextualização funcional da documentação (TROITIÑO, 2012).

No esteio dessa constatação, diversos 
questionamentos emergiram. Um deles, no entanto, se apresentou latente: ao transferir a custódia de um fundo, o fator referencial tomado por proveniência pode sofrer prejuízo? Esse ponto é crucial, pois a constatação afeta todo o sistema classificatório e a organização arquivística decorrente. Apenas para exemplificar uma das possíveis ocorrências, esse Ao transferir a custódia de umfundo, o fator referencial tomado por proveniência pode sofrer prejuízo? Esse ponto é crucial, pois a constatação afeta todo o sistema classificatório e a organização arquivística decorrente. lecionadas três com expressiva presença no cenário nacional, tanto pelo patrimônio que preservam, quanto por sua atuação no campo da organização de arquivos e por possuírem políticas ativas para o incremento de seus tema fica bem evidenciado quando se verifica a confusão ocasionada entre fundos privados de pessoas públicas e documentação de origem pública.

Compreender o procedimento de avaliação pela via extraordinária de incorporação de documentos, identificando os valores e a representatividade do conjunto documental e como os distintos mecanismos empregados para a aquisição de acervos interferem nos quadros de arranjo documental e em seus instrumentos de acesso, pode ser esclarecedor dos recursos organizacionais empregados nas etapas posteriores de tratamento documental.

próprios acervos: o Arquivo Público do Estado de São Paulo (Apesp), o Instituto de Estudos Brasileiros (IEB) e o Centro de Documentação e Memória da Unesp (Cedem).

\section{Sobre a noção de custódia}

Tradicionalmente, a ideia de custódia sobre um acervo arquivístico remete ao zelo pela documentação enquanto bem, englobando a responsabilidade pela preservação física, pelo acesso e, 
não raramente, o cuidado com o uso de seu conteúdo informacional, em termos legais.

Na atualidade, novas formas de custódia ganharam espaço e desvincularam a guarda do documento da propriedade sobre ele. Maria Luisa Conde Villaverde (2007) problematiza a dinâmica do atual contexto político-econômico, afirmando que parte das causas motivadoras da atual tendência em se terceirizar a guarda de documentos deriva da própria sociedade da informação, assim como também da influência direta do mundo das empresas privadas no modelo de "nova gestão pública".

Nesse contexto, novos paradigmas, como o pós-custodial, por exemplo, surgem fomentando tendências de mercado. Contudo, nem sempre correspondem ao conceito de custódia, ainda que, de uma forma ou de outra, incitem a adoção de medidas em nome do emprego de uma "boa gestão administrativa".

Desde os anos 1980, a ideia de era pós-custodial, por muitos considerada manifestação pós-modernista na
Arquivologia, tem ganhado adeptos e sido amplamente divulgada. Surge em resposta à linha tradicionalista, que tem como um de seus grandes autores Sir Hilary Jekinson (1922), mas que acaba por colocar em xeque também linhas mais contemporâneas, como a representada pela record management americana e sua contra resposta, a arquivistica integrada canadense, ambas amplamente enraizadas na abordagem patrimonialista de arquivos, apesar das visões inovadoras que introduzem.

Ao se referirà tendência pós-custodial, Terry Cook (1992) comenta que a realidade do arquivista é frequentemente lógica e funcional, ao invés de física - posição em larga medida fomentada pela emergência' da produção de documentos eletrônicos. Essa abordagem desloca o foco da pércepção do profissional arquivista como curador de um acervo físico para o entendimento de um novo profissional com perfil de gestor da informação.

Os expoentes da Arquivologia portuguesa, Armando Malheiro da Silva e Fernanda Ribeiro, em diversos de seus trabalhos, escritos tanto em conjunto 
quanto individualmente, há alguns anos se colocam em oposição à visão tecnicista e patrimonialista que deriva da abordagem científica, e a favor da pós-custodial de arquivos. Argumentam que, diante da atualidade, a primeira visão se mostra obsoleta face à dinâmica mundial de produção e difusão de informações, postulando uma "viragem do paradigma" (SILVA \& RIBEIRO, 1999).

No final dos anos 1990, desponta a corrente australiana record continuum, discutindo a abordagem adotada para o reconhecimento de valores, uso e pertinência da custódia de documentos. Surge em oposição à abordagem estanque e linear proposta pelo ciclo de vida dos documentos e às dicotomias apresentadas pela corrente americana (records versus archives) e seus correspondentes profissionais (records managers versus archivists). Para o modelo teórico australiano, a gestão documental deve ser contínua e integral, ocorrendo em todo o ciclo de vida do documento. A integração deve/ pode ocorrer no eixo tempo-espaço (UPWARD, 1996).

Na contramão dessas tendências, al- gumas iniciativas de cunho prático em âmbito mundial, amplamente enraizadas no viés patrimonialista, têm surgido e incentivado a preservação física de acervos. Talvez duas de suas expressões mais emblemáticas possam ser representadas pelo Programa Memória do Mundo da Unesco (2002) e pela atuação da ONG Archiveros sin Fronteras.

Do mesmo modo, surge a corrente total archives, trazendo uma nova proposta, na qual arquivos de origem não pública devem ser preservados de igual modo pelo Estado, por serem tão representativos da sociedade quanto qualquer outro (MILLAR, 1998). Configura-se como uma estratégia visando à combinação de arquivos administrativos oficiais com outros de origem privada, de modo a se complementarem (PEARCE-MOSES, 2005).

Diante da atual conjuntura, é fundamental ter clara a diferença entre custódia física e custódia legal. Ligada a fins de preservação da integridade física dos documentos e à acessibilidade ao conjunto de informações neles registradas, cada vez mais a custódia física faz-se de forma independen- 
te da responsabilidade legal sobre a documentação. Em contrapartida, a custódia legal vincula-se à posse e à responsabilidade pela criação de políticas governamentais de acesso ao material, independentemente de sua localização física (PEARCE-MOSES, 2005).

Apesar da forte tendência de desvinculação, ainda hoje não é raro que a custódia física e a custódia legal andem emparethadas, muitas vezes tendo seus conceitos

Apesarda forte tendência de desvinculação, aindà hoje não é raro que a custódia física e a custódia legal andem emparelhadas, muitas vezes tendo seus conceitos mesclados. Evidentemente, a custódia física de documentos implica necessariamente responsabilidade jurídica, porém uma responsabilidade vinculada à garantia de guarda e proteção de arquivos, independente do vínculo de propriedade questão da avaliação e recepção de documentos de outras origens sob tais vieses teóricos.

\section{Instituições}

de guarda de documentos e suas políticas de aquisição de acervos

Recentemente, no mesclados. Evidentemente, a custódia física de documentos implica necessariamente responsabilidade jurídica, porém uma responsabilidade vinculada à garantia de guarda e proteção de arquivos, independente do vínculo de propriedade (CUNHA, 2008).

Normalmente, as correntes da Arquivologia a que nos referimos, assim como os estudos dela derivados, se voltam para uma abordagem sistê-
Estado de São Paulo, o Decreto $n^{\circ}$ 60.145, de 11 de fevereiro de 2014 , dispôs sobre o recolhimento de documentos de guarda permanente, produzidos e acumulados pelos órgãos e entidades da Administração. Pública estadual direta, indireta e fundacional para a Unidade de Arquivo Público do Estado, da Casa Civil. (Autor, data?) Além de determinar o recorte temporal (31/12/1940) utilizado para definir os arquivos submetidos a avaliação, 
também dedica o Artigo $2^{\circ}$, Inciso IV, ao estabelecimento da condição prévia para a incorporação de acervos de origem privada ao Arquivo Público do Estado de São Paulo.

Esse decreto - em larga medida fruto dos encontros do grupo paulista para a revisão da Lei $n^{\circ} 8.159 / 91$, que dispõe sobre a política nacional de arquivos públicos e privados, e para a I Conferência Nacional de Arquivos (2017) - busca regulamentar o sistema de incorporação de documentos fora do sistema de gestão documental do Estado. Revela-se, assim, pela primeira vez, a oficialização de uma política pública para a aquisição de arquivos por parte do governo de São Paulo. Isso não significa que, anteriormente, não tivesse havido iniciativas para a aquisição de arquivos com esse perfil, muito pelo contrário. O Arquivo Público do Estado de São Paulo, desde sua criação, em 1892, pelo Decreto $n^{\circ} 30$, sempre buscou incrementar seu próprio acervo, com documentos produzidos ou não pela administração pública. Como exemplo, podemos citar, já em 1899, a Lei n 666, de 6 de setembro, que determinou que fosse recolhida ao Arquivo Público do Estado de São Paulo toda a documentação anterior ao século XIX pertencente a carrtórios do judi- ciário paulista; e, mais recentemente, a partir da década de 1980, o programa Memorial dos Covernantes, voltado para reunir dentro do Apesp os arquivos pessoais dos principais dirigentes políticos do Estado de São Paulo.

Contudo, neste ensaio, em particular, faremos nossa análise a partir dos estudos de caso do IEB e do Cedem, instituições vinculadas a universidades, custodiadoras de importantes fundos e coleções de origem privada e muito proativas na captação e incorporação de novos acervos de valor histórico e social. Dessa forma, foram levantados dados referentes a essas duas instituições, especialmente em relação àaà missão institucional e formação de acervo. O levantamento de informações se deu por meio de visitas técnicas, entrevistas com os profissionais e responsáveis de cada instituição, consulta aos arquivos administrativos e leitura de bibliografia específica.

\section{Centro de Documentação e Memória da Unesp (Cedem)}

OCentro de Documentação e Memória 
da Universidade Estadual Paulista "Júlio de Mesquita Filho" (Cedem/Unesp) föi criado em 1987 a partir da iniciativa de um grupo de pesquisadores de Humanas que, preocupado com a preservação de documentos e a memória histórica da Unesp, concebeu um centro de documentação e memória para a Universidade - momento de fundamentação de seus marcos de referência que ainda perduram. Surgia o Cedem, em larga medida moldado pela idealização de um núcleo de memória universitária, e também, naquela ocasião, pela ideia de constituir núcleos específicos sobre a memória paulista e sobre documentação regional (UNESP, 1987). Da concepção à concretização, ajustes ao projeto inicial fizeram-se necessários, e os núcleos sobre memória paulista e doçumentação, posteriormente, deram lugar a acervos sobre a memória de movimentos sociais.

Isso abriu um novo leque de possibilidades, diante da ampliação da linha de atuação que o definia. Se, originalmente, o Cedem fora concebido para gerar e abrigar documentos sobre a própria história da Universidade e, assim, atuar em prol da preservação de seus arquivos; ao aceitar arquivos com origem distinta dteve que se reinventar.
Esse processo foi iniciado em 1994, com a entrada da totalidade dos documentos que integravam os acervos de outras instituições, como o Archivio Storico del Movimento Operaio Brasiliano (Asmob/ IAP) e o Centro de Documentação do Movimento Operário Mario Pedrosa (Cemap), por meio de convênio estabelecido. A partir desse momento, o Cedem começa a acolher arquivos sobre movimentos sociais de diversas origens e condições jurídicas - doação, depósito, compra (CAMARCO, 2008).

Durante décadas, os processos de incorporação de acervos tiveram caráter "espontâneo", condicionado a avaliações sem protocolos ou metodologia explicitados. Em 2015, foi definida uma Política de Desenvolvimento de Coleções e Aquisição de Acervos (UNESP, 2015), documento que passou a nortear todas as atividades de expansão do acervo da instituição.

\section{Instituto de Estudos Brasileiros (IEB/USP)}

Idealizado pelo renomado historiador 
Sérgio Buarque de Holanda, o Instituto de Estudos Brasileiros da Universidade de São Paulo surge em 1962 com o objetivo de estudar a sociedade brasileira em seus múltiplos aspectos, constituindo, por um lado, um centro de pesquisa (adquirindo acervos e estimulando investigações) e, por outro, promovendo atividades acadêmicas, como cursos, eventos e publicações (SANCHES, 2011).

Institucionalmente, o IEB entende que documentação e pesquisa são indissociáveis (USP, 2010). Consequentemente, tanto a formação do arquivo da instituição quanto as pesquisas desenvolvidas por seu corpo de docentes, alunos e pesquisadores vinculados. fazem parte da missão institucional. Grandes esforços foram empregados para a garantia dessa vocação. Em sua concepção original, Sérgio Buarque de Holanda idealizou um órgão multidisciplinar e multitemático es- pecializado nos estudos sobre o Brasil. Segundo Caldeira (2002), o historiador pretendia renovar os estudos sobre a História do Brasil a partir de uma perspectiva multidisciplinar, grande novidade para a época. Assim sendo, a ideia da constituição de um acervo voltado para essa finalidade, que fomentasse pesquisas nesse eixo temático, se confundiu inicialmente com a conștituição de uma grande Coleção Brasiliana.

Se originalmente, no projeto de Sérgio Buarque de Holanda, o IEB deveria constituir uma grande Brasiliana por meio da reunião de diversos acervos com esse perfil, com as mudanças de gestão e o corpo de pesquisadores o foco de interesse institucional se voltou principalmente para arquivos de escritores e de artistas vinculados ao modernismo brasileiro, das mais diversas especialidades (USP, 1997). Assim, na atualidade, o IEB tem sob sua responsabilidade a guarda e preservação 
de um significativo conjunto de fundos e coleções de importantes personalidádes brasileiras, como Mário de Andrade, Craciliano Ramos, Fernando de Azevedo, Anita Malfatti, Camargo Guarnieri, João Guimarães Rosa, entre tantos outros, distribuídos entre o Arquivo, a Biblioteca e a Coleção de Artes Visuais - as três grandes divisões adotadas para tratamento documental no IEB.

A USP, anteriormente à criação do IEB, em 1935, já havia adquirido, pelas mãos do então diretor do Departamento de Cultura, Mário de Andrade, a destacada Coleção Alberto Lamego, considerada a primeira brasiliana a ser constituída, e que durante décadas ficou sob a responsabilidade da Biblioteca da então Faculdade de Filosofia, Ciências e Letras - FFCL. Unindo a importância da coleção Lamego à oportunidade de compra de outra significativa brasiliana, a Coleção Yan de Almeida Prado, argumenta Sérgio Buarque de Holanda, "que esta biblioteca, juntamente com a Lamego da FFCL, será um sólido ponto de partida para a estruturação de um grande centro de estudos de alto nível que honrará e dará maior renome internacional à Universidade de São Paulo"' (Processo RUSP no $15537 / 62$ apud CALDEIRA, 2002; p. 99-100).
Desse modo, com a proposta de reunir acervos de valor histórico existentes dentro e fora da Universidade, seria criado o IEB - proposta que já dizia respeito a uma ação estrátégica, no sentido de reunir importantes fontes de pesquisa que subsidiassem suas próprias investigações e, simultaneamente, agregassem prestígio à USP.

Tem início, então, uma atuação crescente de captação de arquivos externos à Universidade e que perdura, inclusive, na atualidade. Segundo Caldeira (2002, p. 103), o ingresso de acervos no IEB, por doação, é predominante, tendo sido continuamente crescente ao longo das décadas, com ênfase no período 1990-1997. Entretanto, também pudemos perceber grande presença de acervos incorporados por compra ou legado (USP, 1997).

\section{Cedem e IEB: semelhanças e dissonâncias}

Tanto o IEB quanto o Cedem foram constituídos administrativamente de 
modo a alcançar determinada autonomia em relação à estrutura universitária-evidentemente, dentro dos limites do possível -, e por isso estão vinculados a níveis hierárquicos superiores.

No caso do Cedem, ainda que criado com espaço físico determinado, acervo documental crescente, equipamentos e infraestrutura adquiridos com a finalidade de proporcionar preservação e acesso à documentação, somente foi institucionalizado em 2003, em nível de coordenadoria vinculada diretamente à Vice-Reitoria (Resolução Unesp n96/2003).

No projeto de criação do IEB, constava que deveria ser vinculado à $F F C L$, ao invés de se subordinar a algum departamento específico. Contudo, no ato de criação do IEB, efetivado pelo Decreto Estadual no 40.346, de 7 de setembro de 1962, que aprovou os Estatutos da Universidade de São Paulo, (ele assumiu nível de Instituto Universitário, com administração própria, supervisionada pela Reitoria (Cf. Arts. $4^{\circ}$ e $5^{\circ}$ ). $O$ atual regimento explicita que o IEB é um órgão de integração da USP, constituindo Instituto Especializado (Resolução RUSP n 5.831/2010).
Tal posição hierárquica nos quadros das universidades proporciona ao Cedem e ao IEB reconhecimento interno como centros responsáveis por preservar importantes documentos históricos de interesse social e, portanto, prestígio agregado à missão universitária em suas três modalidades:, ensino, pesquisa e extensão. Por outro lado, assumem certo valor referencial no que diz respeito ao tratamento arquivístico de documentos no âmbito universitário.

Por meio da análise da totalidade dos acervos, feita com base em visitas técnicas, consulta a instrumentos de pesquisa e relatos dos responsáveis pelos arquivos, notamos que, em ambas as instituições; o perfil dos acervos captados acompantia os interesses da gestão ou do grupo de pesquisadores constituintes do centro no período da aquisição, ao invés de ser determinado pela linha de acervo da instituição em si. Na verdade, a atuação desses grupos de pesquisadores conforma a linha de acervo, chegando a alterá-la de acordo com os interesses envolvidos.

No IEB, o deslocamento de interesse pela reunião de documentos que re- 
fletissem uma grande brasiliana para a formação de um acervo voltado para o modernismo brasileiro - de certo modo, adequação parcial ao conceito de brasiliana - foi reflexo dos interesses de gestões e de pesquisadores atuantes em distintos momentos.

Do mesmo modo, essa tendência pode ser igualmente verificada no Cedem, nascido originalmente para abrigar, além do núcleo de memória universitária, núcleos sobre memória paulista e documentação regional. Ao agregar a temática "movimentos sociais de caráter político" como área de interesse, dividindo espaço com a linha de atuação memória universitária, exclui definitivamente do projeto os núcleos de memória paulista e documentação regional - que, efetivamente, nunca foram constituídos por falta de pesquisadores que os promovessem.

Tanto o IEB quanto o Cedem recentemente estabeleceram e consolidaram políticas de formação de acervo, por meio da elaboração de documentos oficiais: Critérios para Incorporação de Acervos ao IEB/USP (2008); Política de Acervo para o IEB (2010); e Política de Desenvolvimento de Coleções e Aquisição de Acervos (CEDEM, 2015).
No relato de ambas as instituições, a adoção de uma política norteadora para a formação de acervo se revelou, divisor de águas. Para o IEB, quando questionado se o emprego de medidas rígidas de seleção e incorporação de acervos resultou em queda da oferta de documentação à instituição, a resposta foi negativa. Pelo : contrário: em depoimento coletado, houve a afirmativa de que o emprego de critérios e procedimentos claros e transparentes de avaliação de documentos de interesse histórico-cultural agregou credibilidade ao próprio instituto, assim como aos conjuntos documentais por ele abrigados

Em relação ao Cedem, nos poucos meses de vigor da política (estabelecida em novembro de 2015), o que se pode notar é que, pela primeira vez, há regras claras para a incorporação de acervos - antes decidido de forma particularizada pela coordenação ou por iniciativa pontual de funcionários. A partir da adoção da política, foi dada voz ao corpo técnico, que se manifesta por escrito sobre a pertinência ou interesse do conjunto documental ofer-

1 Entrevista realizada com a supervisora do Arquivo do IEB, Elisabete Marin Ribas, em 03/08/2016. 
tado, para fins de instrução do processo e para deliberação do Conselho Consultivo. Houve também a consideração de que a política, em determinados casos, como o de conjuntos documentais menores, é um excesso de burocratização do sistema, segundo percepção pessoal da entrevistada².

No que se refere ao tratamento técnico documental, as duas instituições apresentam propostas e histórico de intervenções bem diferentes, que transparecem não somente em seus instrumentos de pesquisa, mas também nas formas de acesso à documentação.

O IEB, em geral, sempre recebeu conjuntos documentais bem definidos, em.sua maioria arquivos pessoais, mas algumas coleções também, com procedência bem documentada e raras transferências de propriedade. Durante muitos anos utilizou como metodologia, para a organização arquivística, o clássico modelo de organização de arquivos pessoais do CPDOC-FCV (1994). Mais recentemente, vem trabalhando com experimentação e de-

2 Entrevista realizada com a historiógrafa do CEDEM, Jacy Machado Barletta, em 05/08/2016. senvolvendo metodologia própria para a organização de arquivos pessoais, em larga medida pautada na análise documental e categorização, conforme história de vida dos titulares.

O Cedem, talvez por custodiar documentos provenientes de movimentos sociais com caráter político - muitas vezes reunidos na clandestinidade, perdidos e recuperados diversas vezes, com passagem por vários titulares, apresentando elevado grau de dificuldade na identificação da proveniência e ordem original - em geral trata tais documentos de forma articulada, entre fundos e coleções, agrupados fisicamente por critérios variados, como espécie ou gênero documental (periódicos, cartazes, fotografias, livros, documentos textuais, audiovisual). Contudo, a informação sobre a procedência sempre é preservada na descrição ou base de dados correspondente. Ainda que não utilize o modelo de sistema de séries elaborado por Peter Scott (1966), certas opções metodológicas às vezes podem lembrar, mesmo que vagamente, as propostas do autor.

Avaliação documental no sistema extraordinário e organização arquivística 
A noção arquivística de organização documental está intimamente ligada ao processo de contextualização do fundo, sendo esta uma questão quase pacífica entre os diversos pesquisadores ou profissionais que trabalham em arquivos. Contudo, o que raramente se discute são os distintos parâmetros possíveis a ser adotados com essa finalidade.

O modo como o arquivo é avaliado deve obrigatoriamente levarem consideração distintos elementos: 1) proveniência; 2) completude enquanto conjunto orgânico de documentos ou de informações; 3) caracterização das espécies e tipos documentais; 4) conteúdos informacionais; 5) histórico do titular e do contexto em que atuou: e 6) história arquivística. Todos são critérios fundamentais no processo de organização arquivística, que obrigatoriamente devem aparecer no momento da ávaliação e valo- ração de um acervo a ser incorporado a uma instituição de guarda de documen-, tos.

Estabelecer critérios de análise que levem em conta a origem dos documentos é imprescindível para

a contextualização funcional da produção documental. Se o trabalho de organização de fundos arquivísticos deve necessariamente passar pelo entendimento das deve.

causas que motivaram a criação dos documentos, o reconhecimento de seus valores sociais, históricos e testemunhais também deve. Por isso, a produção documental precisa ser considerada nas avaliações de documentos, mesmo no sistema extraordinário de recolhimento, possibilitando, assim, a identificação de referenciais a ser utilizados, posteriormente, para o agrupamento de informações e documentos nos distintos níveis hierárquicos em 
que se encontram, dentro de um plano de classificação arquivística capaz de evidenciar a organicidade inerente à documentação.

Nesse processo, a identificação documental assume papel preponderante e determinante, por se encarregar de fornecer os subsídios metodológicos necessários para o reconhecimento do valor do conjunto de documentos. Assim como Ramón Alberch Fugueras (2003), entendemos que a identificação documental é inseparável da avaliação documental, que tem justamente como objeto preferencial de análise as séries e os tipos documentais.

Ambas constituyen necesariamente un paso previo ineludible para proceder de manera coherente a la clasificación, descripción, y recuperación de los documentos y de la información. Así, pues, nos encontramos con que la identificación se convierta en el inicio de un proceso secuencial que hay que vincular - estrecha y especialmente - a la evaluación y clasificación, ya que necesita conocer (es decir, identificar y caracterizar) los fondos y las secciones, las subsecciones, las series y las tipologías documentales $y$, en último término, los expedientes y las unidades documentales (ALBERCH ALBERCH FUCUERAS, 2003, p. 109).

Dessa forma, desempenha importante papel para a organização arquivística, possibilitando um trabalho com maior eficiência, já que a partir dela é possível subsidiar as etapas posteriores a sua própria aplicação, como classificação, avaliação e descrição, entre outras (TROITIÑO \& FONSECA, 2016).

Segundo Ana Célia Rodrigues (2008), a identificação documental se destaca no tratamento de documentos de arquivo, por colaborar para a compreensão da natureza dos arquivos, de suas particularidades, e viabilizar a contextualização informacional. Dessa forma, ao pensarna preservação de arquivos pessoais - grande parcela 
dos acervos custodiados pelas instituições aqui estudadas -, deve ser levada em conta a origem da documentação, os modos de produção e acumulação dos documentos, a trajetória do acervo ea diversidade tipológica dos registros.

Arquivos pessoais constituem fontes valiosas de pesquisa porque são capazes de refletir aspectos da realidade social não contemplados por fundos institucionais, normalmente regidos pelas normas do direito administrativo. Revelam-se, assim, mais próximos do viver e atuar em sociedade. Essa compreensão passa pelo entendimento dos tipos documentais e das relações orgânicas que permeiam a documentação de ordem pessoal, como elementos cruciais para o seu reconhecimento enquanto arquivo.

A identificação documental também pode contribuir para o reconhecimento dos tipos documentais, pois possibilita a análise, tanto individual quanto articulada, das unidades documentais dentro do conjunto orgânico de origem, revelando, além das características próprias de cada registro, elementos do contexto de acumulação e guarda, bastante significativos para a compreensão da constituição do fundo (TROITIÑO \& FONSECA, 2016).

\section{Algumas considerações}

Neste ensaio, realizamos algumas considerações introdutórias, com base nos preceitos da Arquivologia, sobre a questão da incorporação de documentos com informações de valor histórico a instituições de custódia, paralelamente ao sistema ordinário de transferência de documentos. Documentos oriundos de diversas proveniências, que não a administrativa da instituição que os receberá, costumam ser avaliados e recolhidos, mas não institucionalizados. Esse é um dado significativo, pois oferece sentidos novos ao conjunto de documentos, especialmente por conviverem com outros arquivos ou coleções pertencentes à mesma linha temática.

Com base no estudo de caso do IEB e do Cedem, foram feitas reflexões sobre a questão da avaliação dentro e fora de políticas de incorporação de acervos estabelecidas; e sobre como a documentação incorporada se articula com a totalidade do acervo custodiado pela instituição. Importa dizer que essa é uma pesquisa em curso. Por isso, não consideramos os aspectos aqui anali- 
sados como uma discussão encerrada, mas antes uma reflexão de valor intro- dutório ao tema, conscientes de que ainda há muito a se explorar.

\section{Referências}

ALBERCH FUGUERAS, Ramón. Los archivos, entre la memoria historica y la sociedade del conocimiento. Barcelona: UOC, 2003.

BATISTA, Marta Rosseti (Coord.). ABC do IEB. Guia Ceral do Acervo. São Paulo: IEB/EDUSP, 1997.

CALDEIRA, João Ricardo de Castro. IEB: origem esignificados. Uma análise do Instituto de Estudos Brasileiros da Universidade de São Paulo. São Paulo: Oficina do Livro Rubens Borba de Moraes; Imprensa Oficial do Estado, 2002.

CAMARCO, Célia Reis (Org.). Guia do Acervo-Cedem. São Paulo: Cedem/Unesp, 2008.

CEDEM (Centro de Documentação e Memória - Universidade Estadual Paulista). Política de Desenvolvimento de Coleções e Aquisição de Acervos. São Paulo: Cedem, 2015. 8. p. Não Publicado.

CPDOC (Centro de Pesquisa e Documentação de História Contemporânea do Brasil - Fundação Cetúlio Vargas). Procedimentos técnicos adotados para a organização de arquivos privados. 2. ed. Rio de Janeiro: CPDOC/FCV, 1994.

CONDE VILLAVERDE, Maria Luisa. Un aspecto de la privatización de los servicios públicos. Arquivo \& Administração. Rio de Janeiro: AAB, 2007. p. 51-63.

COOK, Terry. The concept of the archival fonds in the post-custodial era: theory, problems and solutions. Archivaria, [S.I.], jan. 1992.

CUNHA, Murilo Bastos da; CAVALCANTI, Cordélia Robalinho de Oliveira. Dicionário de biblioteconomia e Arquivologia. Brasília: Briquet de Lemos Livros, 2008.

EDMONDSON, Ray. Memória do Mundo. Diretrizes para a Salvaguarda do Patrimônio Documental. [S.I.]. UNESCO, Divisão da Sociedade da Informação, 2002. Disponível em <http://mow.arquivonacional.gov.br/images/pdf/Diretrizes_para_a salvaguarda do patrim\%C3\%B4nio documental.pdf>. Acesso em: 9 set. 2016.

JENKINSON, HILARY. Manual of archive administration. Oxford: Claredon Press, 1922.

MILLAR, Laura. Discharging our debt: the evolution of the Total Archives concept in English Canada. Archivaria, [S.I.], jan. 1998.

PEARCE-MOSES, Richard. Aglossary of archival and records terminology. Chicago: Society of American Archivists, 2005.

RIBEIRO, Fernanda. A arquivística como disciplina aplicada no campo da ciência da informação. Perspectivas em Cestão \& Conhecimento, João Pessoa, v. 1, n. 1, p. 59-73, jan./jun. 2011. 
RODRICUES, Ana Célia. Diplomática contemporânea como fundamento metodológico da identificação de tipologia documentalem arquivos. 2008. Tese (Doutorado em História Social) - Faculdade de Filosofia, Letras e Ciências Humanas, Universidade de São Paulo, São Paulo. 2008

SANCHES, Rodrigo Ruiz. Sérgio Buarque de Holanda na USP. Sociedade e Estado. Brasília, v. 26, n. 1, p. 241-259, abr. 2011

SCOTT, P. The Record Group concept: a case for abandonment. The Americari Archivist, [S.I. . v. 29, n. 4, p. 493-504, out. 1966.

SILVA, Armando Malheiro da; RIBEIRO, Fernanda; RAMOS, Julio; REAL, Manuel Luís. Arquivística.

Teoria e prática de uma ciência da informação. Porto: Afrontamento, 1999.

TROITIÑO, Sonia. Cuestiones en torno a la transferencia de la custodia de los documentos entre archivos públicos. Ibersid: Revista de sistemas de informacióny documentación, Zaragoza, Espanha, v. 6, p. 127-133, 2012.

TROITIÑO, Sonia; FONSECA, Gabrieli Aparecida da. A aplicabilidade da identificação documental em arquivos pessoais: uma reflexão. Ibersid: Revista de sistemas deinformacióny documentación, Zaragoza, Espanha; V. 10, n. 1, p. 33-40, jan./jun. 2016.

USP (Universidade de São Paulo). Instituto de Estudos Brasileiros (IEB). ABC do IEB: guia geral do acervo. São Paulo: Edusp, 7997.

Instituto de Estudos Brasileiros (IEB). Critérios para Incorporação de acervos ao IEB, 2008. In: Guia do IEB: o acervo do Instituto de Estudos Brasileiros. São Paulo: IEB, 2010.

Instituto de Estudos Brasileiros (IEB). Guia do IEB: o acervo do Instituto de Estudos Brasileiros. São Paulo: IEB, 2010.

Instituto de Estudos Brasileiros (IEB). Política de Acervo para o IEB, 2010. In: Cuia do IEB: o acervo do Instituto de Estudos Brasileiros. São Paulo: IEB, 2010.

UPWARD, Frank. Structuring the Records Continuum - part one: postcustodial principles and properties. Archives and Manucscripts, Austrália, v. 24, n. 2, 1996. 